\title{
Wide dynamic range 500 fA sensitivity current measurement instrument
}

\author{
Anatoly Pelemeshko ${ }^{1, *}$, Aleksey Styuf ${ }^{1}$, Vitaliy Prokopyev ${ }^{1}$, Yuri Prokopyev $^{1}$, and \\ Alexander Zadorozhny ${ }^{1}$ \\ ${ }^{1}$ Novosibirsk State University, 630090 Novosibirsk, Russia
}

\begin{abstract}
Main technical features of Low Energy Charged Particle Sensor (LECPS) are described, taking into account LECPS high sensitivity, wide dynamic range, and conditions of in-flight operation on-board a satellite. LECPS input cascade is capable of current measurement as low as $1 \mathrm{pA}$ within a $120 \mathrm{~dB}$ dynamic range, providing error level below $20 \%$. Statistical calculations of acquired data, measuring time considerations and implementation of input cascade auto-calibration technique were applied to gain the best possible stability and accuracy over $-20^{\circ}$ to $+50^{\circ} \mathrm{C}$ operation temperature.
\end{abstract}

\section{Introduction}

Division for Atmospheric Research at Novosibirsk State University has been designing onboard space devices for the last 35 years. Most activities are devoted to automation of space experiment by creating measuring equipment for inflight operation that meet strict requirements of space environment, high reliability, mass and power consumption constraints. Another scope of the laboratory is telemetry and interface devices that simplify connection of external probes to power and information interfaces of a satellite.

Low energy charged particle flux has always been a matter of concern for spacecraft engineers since it inevitably leads to satellite charging and results in an uncontrolled electrostatic discharge [1]. Main sources of particle flux are atmospheric plasma, solar particle flux and plasma thrusters [2]. Either a satellite is sent to a new orbit or new design/materials are implemented within a satellite it is necessary to investigate a chargedischarge phenomena by providing in-flight experimental data.

An Low Energy Charged Particle Sensor (LECPS) was designed at the Division for Atmospheric Research to allow in-flight monitoring of low energy charged particle flux. LECPS photo and specifications are presented on Figure 1.

LECPS is meant to be placed on the outer side of a satellite. According to the existing space environment model and industry requirements, the device must register current within $1 \mathrm{pA}$ to $100 \mathrm{nA}$ range. For this reason, LECPS is equipped with a wide dynamic range current meter obtaining a $500 \mathrm{fA}$ sensitivity and operating in a temperature range from $-20^{\circ}$ to $+50^{\circ} \mathrm{C}$ ensuring an error level below $20 \%$. A light weight, small dimensions and low power consumption of the device combined with a 15 year lifetime provides

\footnotetext{
*Corresponding author: pelemeshko55@,gmail.com
} 
possibilities for integration into nearly every up to date space mission. LECPS information interface is compatible with a widespread MIL-STD-1553B [3]. Compliance with all stated requirements was confirmed by accurate ground tests.

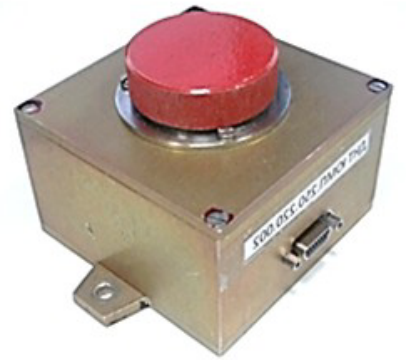

$\begin{array}{ll}\text { sensitivity: } & 500 \mathrm{fA} \\ \text { dynamic range: } & 1 \mathrm{pA}-100 \mathrm{nA}(120 \mathrm{~dB}) \\ \text { error level: } & 20 \% \\ \text { dimensions: } & 70 \times 70 \times 54,5 \mathrm{~mm}^{3} \\ \text { weight: } & 0,47 \mathrm{~kg} \\ \text { power consumption: } & 1,5 \mathrm{~W} \\ \text { temperature range: } & -20^{\circ} \text { to }+50^{\circ} \mathrm{C} \\ \text { lifetime: } & 15 \text { years } \\ \text { interface: } & \text { MIL-STD-1553B }\end{array}$

Fig. 1. Low Energy Charged Particle Sensor (LECPS) photo and specifications.

\section{Solutions}

Figure 2 presents functional diagram of the LECPS. An input cascade consists of a lowinput current pre-amplifier as a current-to-voltage converter and a programmable gain amplifier (PGA). As the result, an input signal has a leakage current less than $100 \mathrm{fA}$, while output signal can be multiplied by factor of 1, 10, 100 and 1000. PGA output signal drives an ADC (12 bit, $200 \mathrm{~Hz}$ ) that is integrated into a microcontroller (MCU) periphery. MCU performs data acquisition, controls a gain value of PGA, and interfaces to an external MILSTD-1553B command bus. An input relay allows measuring of "zero-level signal" at all gains thus performing online calibration to get rid of input cascade offset caused by temperature drift and parts aging.

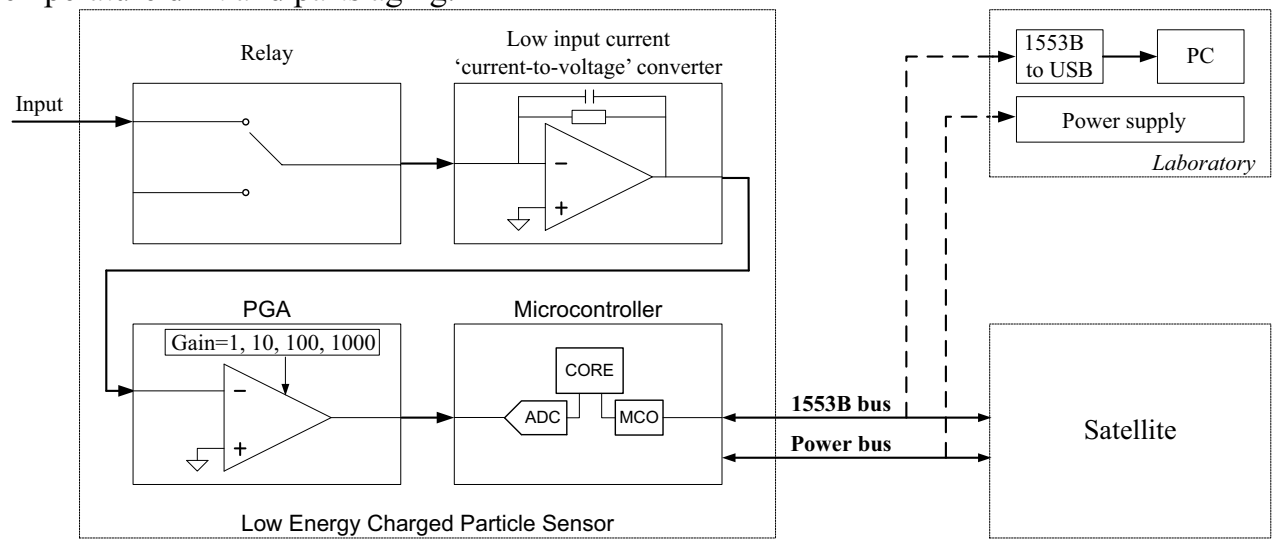

Fig. 2. The functional scheme of LECPS: current meter input cascade and data acquisition.

To obtain acceptable ADC data array for further calculations the following requirements for electronic components should be considered:

- $\quad$ input operational amplifier (in a whole temperature range):

$\circ$ input bias current below $100 \mathrm{fA}$;

$\circ$ offset voltage below $100 \mathrm{uV}$;

- low temperature drift less than $10 \mathrm{uV} /{ }^{\circ} \mathrm{C}$

○ unity gain below $1 \mathrm{MHz}$;

- $\quad$ PGA (in a whole temperature range): 
- digitally programmable gain;

○ selectable gains $1,10,100,1000$;

- low temperature drift (referred to input) less than $10 \mathrm{uV} /{ }^{\circ} \mathrm{C}$

- $\quad \mathrm{ADC}$ (integrated into microcontroller):

$\circ$ sufficient resolution -12 bit;

- data acquisition rate -10 KSPS or higher.

Time chart of a measuring period is presented in Figure 3. This procedure consists of auto-calibration phase (relay off) and current value acquisition phase (relay on). During each phase the MCU successively switch gain value of a PGA and calculates a corresponding average value.

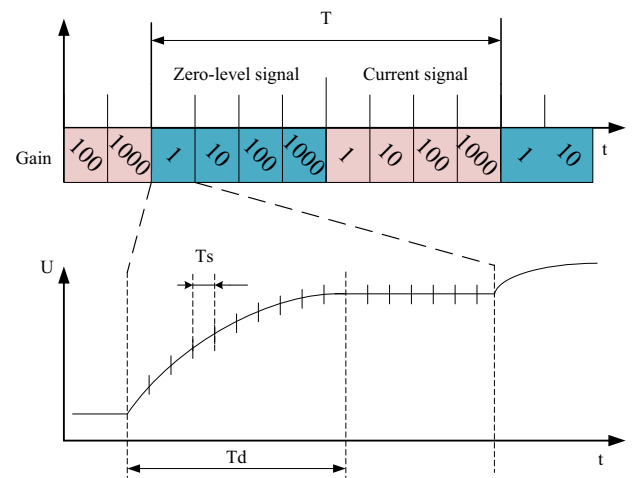

Fig. 3. Survey timing diagram of LECPS measuring cascade: $\mathrm{T}$ - single measurement time, Ts ADC time survey, Td - "dead time".

Obviously, both a relay switch and a gain change cause transients on the output of input cascade. Hence, MCU skips ADC values during a defined "dead time" Td to avoid transients effecting calculations. Nevertheless, the ADC unit is still kept operational to maintain electrical circuitry at steady state. The estimated Td time is $100 \mathrm{~ms}$ for gain values 100 and 1000, and is negligibly low for gain values 1 and 10 .

A calculated average value is transferred to a host device via a MIL-STD-1553B compliant interface, supported by $\mathrm{MCU}$ due to an integrated peripheral unit. During inflight operation LECPS is linked to MIL-STD-1553B command bus of a satellite on board computer. For the purpose of ground tests a standard 1553B-to-USB converter offers connection to any laboratory PC or laptop (see Figure 2). In this case all measured data is visualized in a specially designed software monitor.

\section{Results}

A standard deviation of a resulting current value was studied as a function of number of ADC values (e.g. storage time). This was done to ensure sufficiency of electrical filters at schematic level. The result is shown in Figure 4. An evident $\frac{1}{\sqrt{n}}$ dependency demonstrates that ADC input signal has a "white noise" nature. A $10 \mathrm{sec}$ storage time was used during future calibration procedure to provide a standard deviation below $20 \%$ at low input current values.Calibration of LECPS in the completely input current range from $1 \mathrm{pA}$ to $100 \mathrm{nA}$ was carried out using Keithley SourceMeter 2611B. A special triaxial cable technique and a metal shield was used to avoid electromagnetic disturbances affecting signal at input current below $50 \mathrm{pA}$. 


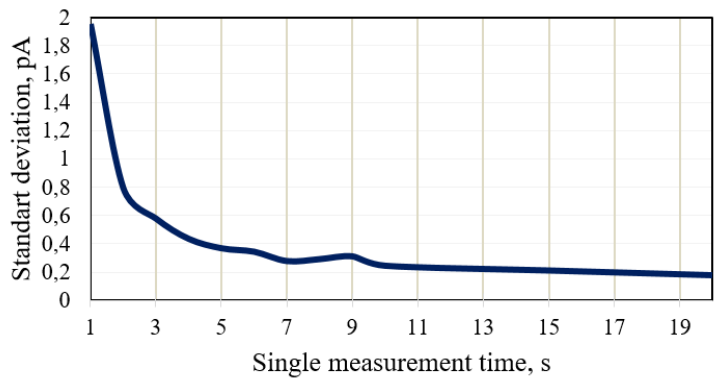

Fig. 4. The dependence of the standard deviation on measurement time.

Temperature stability of the LECPS was investigated during tests in a climatic chamber in an extended temperature range from $-55^{\circ}$ to $+75^{\circ} \mathrm{C}$. Figure 5 exhibits advantage of autocalibration implementation. As the result, auto-calibration technique leads to a reduction of the calculated current value change from 10000 to $100 \mathrm{ADC}$ quants.

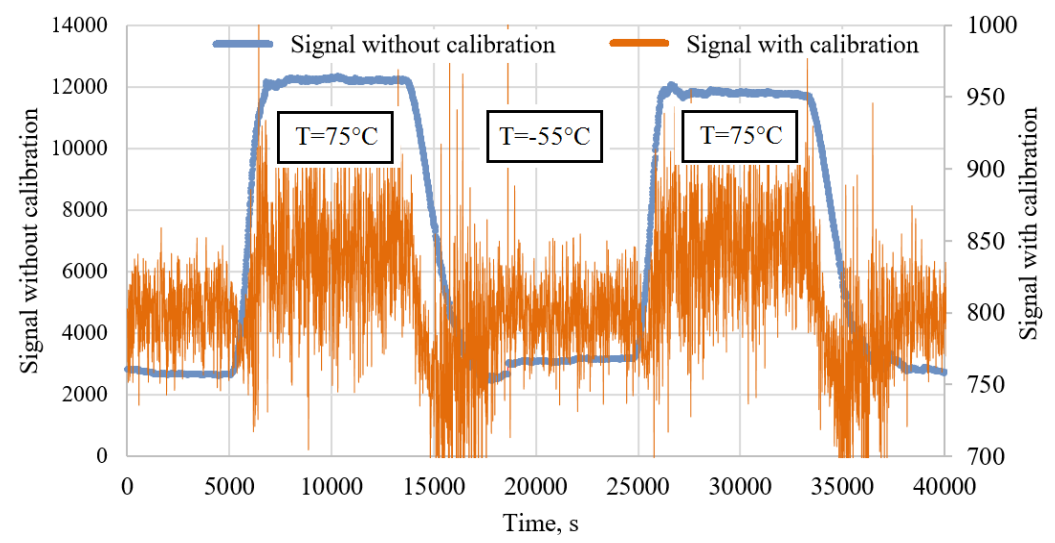

Fig. 5. The measurements at temperature $-55^{\circ} \mathrm{C}$ and $+75^{\circ} \mathrm{C}$.

\section{Conclusion}

A complete design cycle was carried out to create the LECPS - wide dynamic range 500 fA sensitivity current measurement instrument. Precise ground tests proved LECPS temperature stability and metrological characteristics, as well as ability to be operated on board a satellite.

\section{References}

1. L. Aristov, M. S. Borodin, et al, Nauchno-tehnicheskie razrabotki KB "Saljut" 3, 327, (2011) (in Russian)

2. S. V. Balashov, V. V. Ivanov, et al, Reshetnevskie chtenija 46, (2005) (in Russian)

3. Condor Engineering, Inc, MIL-STD-1553 Tutorial (1600100-0028), (2000) 